Check for updates

Cite this: RSC Adv., 2018, 8, 15487

Received 4th January 2018

Accepted 19th March 2018

DOI: $10.1039 / c 8 r a 00081 f$

rsc.li/rsc-advances

\section{UHPLC-Q-TOF-MS/MS-oriented characteristic components dataset and multivariate statistical techniques for the holistic quality control of Usnea $\uparrow$}

\author{
Yiran Jin, ${ }^{\text {ab }}$ Yinghua Ma, ${ }^{\text {ac }}$ Weiwei Xie, ${ }^{a}$ Ludan Hou, ${ }^{a}$ Huijun $\mathrm{Xu}{ }^{a}$ Kerong Zhang, ${ }^{d}$ \\ Lantong Zhang (DD) and Yingfeng Du*a
}

The holistic quality evaluation of Traditional Chinese Medicine (TCM) is confronted with significant challenges due to its extreme chemical complexity. In this study, a sensitive strategy based on ultrahigh-performance liquid chromatography-triple/time-of-flight mass spectrometry (UHPLC-Q-TOF-MS/ MS) and chemometric analysis was established and validated for the qualitative and semi-quantitative analyses of characteristic components in Usnea. First, three mass spectrometry fragmentation patterns of phenolic acid standards were studied and summarized. Then, an extract of this herb was analyzed by the full-scan MS spectra and identified by extracted ion chromatography (XIC). Based on the abovementioned methods, a total of 38 compounds ( 8 dibenzofurans, 11 didepsides, 13 depsidones, and 6 mono-substituted phenyl rings) were identified. Subsequently, the qualities of Usnea samples from different regions were evaluated by the semi-quantitative analysis based on their relative peak areas. Furthermore, principal component analysis (PCA) was performed to compare the Usnea herbs and to find possible diagnostic chemical components. This novel and powerful strategy could provide a potential approach for the holistic quality control of TCM.

\section{Introduction}

Usnea belongs to the Usnea genus and originates from the dried lichen body of Usnea longissima Ach. It is mainly distributed in Sichuan, Yunnan, Zhejiang, and Shanxi provinces in China. For hundreds of years, this plant has been used in folk medicine to protect the liver, clear the heat, and remove the toxins as is recorded in several Materia Medica books such as "Compendium of Materia Medica" and "The Dictionary of Medicinal Plant". Although it also exhibits antioxidant, antineoplastic, anti-allergic, antimicrobial, analgesic, antipyretic, cytotoxic, and antiviral properties in clinic, it is mainly known for its antiinflammatory and anti-microbial properties in the treatment of cough and rheumatism..$^{1-8}$ Simultaneously, it is often consumed as tea or as a healthy drink. ${ }^{9-11}$

Phytochemical studies demonstrate that the members of Usnea genus contain phenolic acids, steroids, triterpenoids,

\footnotetext{
${ }^{a}$ Department of Pharmaceutical Analysis, School of Pharmacy, Hebei Medical University, Shijiazhuang, Hebei, 050017, P. R. China.E-mail: zhanglantong@263. net; yingfengdu@hotmail.com; Fax: +86-311-86266419; Tel: +86-311-86266419; +86-311-86265625

${ }^{b}$ The Second Hospital of Hebei Medical University, Shijiazhuang, Hebei, 050000, P. R. China

${ }^{c}$ Children's Hospital of Hebei Province, Shijiazhuang, Hebei, 050031, P. R. China ${ }^{d}$ Applied Biosystems Trading Co., Ltd., Beijing Branch Office, Beijing 100027, China $\dagger$ Electronic supplementary information (ESI) available. See DOI: 10.1039/c8ra00081f
}

and polysaccharides. ${ }^{12,13}$ Among them, the types of phenolic acids found in the lichens of Usnea genus mainly include dibenzofurans, didepsides, depsidones, and monosubstituted phenyls. ${ }^{13}$ Recently, phenolic acids were believed to be the main bioactive constituents in the lichens of Usnea genus due to their various activities such as anti-microbial, anti-cancer, and anti-inflammatory. ${ }^{\mathbf{1 4 - 1 6}}$ However, according to the reports, only a few chemical ingredients have been isolated from Usnea. ${ }^{17,18}$ In our previous study, a large number of phenolic acids were detected in Usnea by MS, and most of them were at low levels. ${ }^{19}$ It is well-known that Traditional Chinese Medicine (TCM) is commonly believed to operate due to synergistic effects of all of the major and minor components in the medicines. ${ }^{20,21}$ Moreover, many factors such as different origins can affect the quality of TCM. Therefore, it is critically important to explore a more scientific, systematic, and strongly operated evaluation method that canhelp maintain the inherent qualities of TCMs so as to ensure their safety, efficacy, and batch-to-batch consistency. At present, as is observed in the recent studies, only a few quantitative markers have been selected for the quality evaluation of Usnea, ${ }^{22-24}$ which severely restricts its in-depth study and clinical application. Although a HPLC method has been developed for the analysis of usnic acid in this plant, this method mainly focuses on the quantitative determination of single components and also cannot reflect the intrinsic qualities of Usnea. Therefore, the in-depth studying of a qualitative and semi-quantitative 
analytical strategy on the basis of the active ingredients in Usnea is of great significance for its pharmacodynamics and comprehensive quality control.

Recently, HPLC coupled with Q-TOF-MS has been used in ingredient analysis and metabolite detections. ${ }^{25-27}$ Among the multifarious LC platforms, UHPLC holds advantages over HPLC because of its higher speed, higher detection sensitivity, increased specificity, and enhanced repeatability. In addition, Q-TOF-MS provides accurate precursor and product ion information with a mass error of less than $5 \mathrm{ppm}$, which authentically increases the characterization and dependability of the compound..$^{28,29}$ The recent decade has witnessed an increasingly vital role of high-resolution mass spectrometry (HRMS) in complex chemical profiling and highly sensitive quantitative analysis of medicinal herbs. The HRMS system can provide the acquisition of full-scan MS spectra and fragment ion spectral datasets for compounds by virtue of on-line and off-line techniques, enabling the overall consideration of MS and MS/MS spectra for the identification of both target and non-target compounds. In previous studies, it was challenging and errorprone to monitor the relatively small signals from the complex chemical background in full-scan mass chromatograms. $^{30,31}$ To detect as many metabolites as possible, a novel approach combining multiple mass defect filter (MMDF) and dynamic background subtraction (DBS)-dependent on-line data acquisition is used to identify the chemical composition that has explicit mass defect values. ${ }^{32}$ On the other hand, the effective multiple data-mining techniques involved in extracted ion chromatography (XIC), mass defect filtering (MDF), product ion filtering (PIF), and neutral loss filtering (NLF) are employed to further identify and analyze the compounds. Because of the combined use of the above-described techniques, the detection and identification of herbal components becomes easier and faster than before. Furthermore, multivariate statistical analysis methods such as PCA are performed to provide more information about the chemical differences in TCMs. ${ }^{33,34}$ These approaches can be used to process tremendous datasets of TCM samples by showing a two-dimensional space of the variable metabolic profile.
The aim of this study was to develop a novel analytical strategy for the comprehensive quality control of Usnea. First, the fragmentation patterns of three reference substances were studied and summarized. Then, a sensitive method based on on-line data acquisition combined with comprehensive data processing techniques was established for the identification of phenolic acids in Usnea. Next, a semi-quantitative analysis of Usnea samples based on the relative peak areas of the 38 identified compounds was performed in 25 batches of Usnea samples collected from various regions. Meanwhile, PCA was conducted to disclose the possible characteristic components resulting in quality differences in the Usnea samples. It is believed that this novel strategy could be valuable for the quality control of Usnea and other TCMs.

\section{Materials and methods}

\subsection{Chemicals and materials}

Usnic acid was purchased from Shanghai Sunny Bio-technology Co., Ltd. Diffractaic acid was obtained from Shanghai Yuanye Bio-technology Co., Ltd. Evernic acid was purchased from Shanghai Bohu Bio-technology Co., Ltd. The purities of the abovementioned ingredients were more than $98 \%$ according to HPLC analysis. HPLC-grade methanol (Tedia, USA), formic acid (Dikma Technologies Inc., USA), and ammonium acetate (Fisher Scientific, USA) were used in the mobile phase. Redistilled water was prepared in our own lab using the Milli-Q water purification system (Millipore, ELIX100, USA).

\subsection{Plant materials and sample preparation}

Twenty-five batches of Usnea samples (Table 1) were acquired from different regions in China. The Usnea samples, identified by Prof. Lianhuai Li from Department of Pharmacognosy in Hebei Medical University, were deposited in the College of Pharmacy Laboratory of Hebei Medical University, Shijiazhuang, China.

Dried Usnea samples were crushed into fine powder so that they could be passed through 60 mesh screens. An amount of $0.1 \mathrm{~g}$ of Usnea powder was extracted with $25 \mathrm{~mL}$ of $100 \%$

Table 1 Information on the 25 batches of Usnea samples

\begin{tabular}{|c|c|c|c|c|c|}
\hline Sample & Source & Collection time & Sample & Source & Collecting time \\
\hline S1 & Zigong, Sichuan (AHBZ) & 2015.04 & S13 & Fanxiong, Yunnan (AHBZ) & 2015.04 \\
\hline $\mathrm{S} 2$ & Zigong, Sichuan (AHBZ) & 2015.04 & S14 & Fanxiong, Yunnan (AHBZ) & 2015.04 \\
\hline S3 & Zigong, Sichuan (AHBZ) & 2015.04 & S15 & Fanxiong, Yunnan (AHBZ) & 2014.04 \\
\hline S4 & Zigong, Sichuan (AHBZ) & 2015.05 & S16 & Fanxiong, Yunnan (AHBZ) & 2015.05 \\
\hline S5 & Zigong, Sichuan (AHBZ) & 2015.07 & S17 & Zigong, Sichuan (HBAG) & 2015.09 \\
\hline S6 & Zigong, Sichuan (AHBZ) & 2015.09 & S18 & Zigong, Sichuan (HBAG) & 2015.09 \\
\hline S7 & Zigong, Sichuan (AHBZ) & 2015.09 & S19 & Zigong, Sichuan (HBAG) & 2015.09 \\
\hline S8 & Jinhua, Zhejiang (AHBZ) & 2015.04 & $\mathrm{~S} 20$ & Jinhua, Zhejiang (HBAG) & 2015.09 \\
\hline S9 & Jinhua, Zhejiang (AHBZ) & 2015.04 & S21 & Jinhua, Zhejiang (HBAG) & 2015.09 \\
\hline S10 & Jinhua, Zhejiang (AHBZ) & 2015.04 & $\mathrm{~S} 22$ & Jinhua, Zhejiang (HBAG) & 2015.09 \\
\hline S11 & Jinhua, Zhejiang (AHBZ) & 2015.05 & $\mathrm{~S} 23$ & Fanxiong, Yunnan (HBAG) & 2015.09 \\
\hline \multirow[t]{2}{*}{ S12 } & Jinhua, Zhejiang (AHBZ) & 2015.05 & $\mathrm{~S} 24$ & Fanxiong, Yunnan (HBAG) & 2015.09 \\
\hline & & & S25 & Fanxiong, Yunnan (HBAG) & 2015.09 \\
\hline
\end{tabular}


methanol in an ultrasonic bath $(40 \mathrm{kHz}, 500 \mathrm{w})$ for $30 \mathrm{~min}$. An additional quantity of $100 \%$ methanol was added to compensate for the lost weight. Then, the extracted solution was centrifuged for $10 \mathrm{~min}$ at $150000 \mathrm{rpm}$ and filtered through a 0.2 $\mu \mathrm{m}$ GHP filter (Mfd. by Waters Corporation, USA). Afterwards, the supernatant was transferred to a clean polypropylene tube. An aliquot of $5 \mu \mathrm{L}$ from each sample was injected into the UHPLC-Q-TOF-MS/MS system for further analysis.

\subsection{Preparation of standard solutions}

Reference standards were accurately weighed and then dissolved in methanol to yield standard stock solutions for usnic acid, evernic acid, and diffractaic acid at concentrations of $0.400 \mathrm{~g} \mathrm{~L}^{-1}, 0.408 \mathrm{~g} \mathrm{~L}^{-1}$, and $0.392 \mathrm{~g} \mathrm{~L}^{-1}$, respectively. Then, each stock solution was mixed with methanol to prepare a final mixed standard solution. The working solutions were stored at $4{ }^{\circ} \mathrm{C}$ for further analysis.

\subsection{UPLC-Triple TOF-MS conditions}

UHPLC-Q-TOF-MS/MS analysis was conducted on the Shimadzu UHPLC system (Kyoto, Japan) coupled with the triple TOFTM $5600^{+} \mathrm{MS} / \mathrm{MS}$ system (AB SCIEX, CA, USA). The chromatographic separation was accomplished on a Kinetex $\mathrm{C}_{18}(100 \mathrm{~mm}$ $\times 3.0 \mathrm{~mm}, 2.6 \mu \mathrm{m})$ column with a Security Guard UPLC $\mathrm{C}_{18}$ column $(4.0 \mathrm{~mm} \times 3.0 \mathrm{~mm}, 2.6 \mu \mathrm{m})$ (Phenomenex, Torrance, CA, USA), and the column oven was maintained at $25{ }^{\circ} \mathrm{C}$. The mobile phase consisted of water containing $0.1 \%$ formic acid as well as $4 \mathrm{mmoL} \mathrm{L}{ }^{-1}$ ammonium acetate (A) and methanol (B)

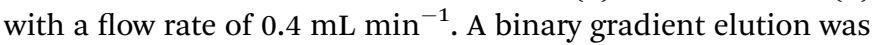
employed, and the consecutive program was as follows: $5-75 \%$ B from 0 to $3 \mathrm{~min}, 75-85 \%$ B from 3 to $15 \mathrm{~min}, 85-95 \%$ B from 15 to $20 \mathrm{~min}$, and $95-98 \% \mathrm{~B}$ from 20 to $25 \mathrm{~min}$; later, the column was returned to its starting conditions for $30 \mathrm{~min}$ for column balance.

The mass spectrometer with a Duo-Spray ${ }^{\mathrm{TM}}$ source was operated in the negative ion electrospray mode, and the parameters of the MS/MS detector were as follows: ion spray voltage: $-4500 \mathrm{kV}$; turbo spray temperature: $550{ }^{\circ} \mathrm{C}$; curtain gas: 25 psi; nebulizing gas (GAS1): 55 psi and TIS gas (GAS2): 55 psi; and declustering potential (DP): $-60 \mathrm{~V}$. For the full MS-IDA (information-dependent acquisition)-8MS/MS analysis, the eight most intense fragment ions of each analyte that exceeded $100 \mathrm{cps}$ counts were selected for the survey scan, and the MS/MS experiments were run in the scan range from $\mathrm{m} / \mathrm{z} 100$ to $\mathrm{m} / \mathrm{z}$ 1000 with $250 \mathrm{~m}$ of accumulation time for full MS and $100 \mathrm{~m}$ of accumulation time for MS/MS experiments. The collision energy (CE) was set at $-30 \mathrm{eV}$, and the collision energy spread (CES) was $15 \mathrm{eV}$ in the MS/MS experiments. The IDA criteria were given to ions that matched the mass defect window to obtain the MS/MS spectra. Simultaneously, real-time MMDF and DBS were used to fulfill the IDA criteria. To get convincing results, an automated calibration delivery system (CDS) was used to automatically calibrate MS and MS/MS with every 6 samples in our study.

The UHPLC-Q-TOF-MS data of the extracted samples were analysed using the PeakView ${ }^{\circledR}$ Software (AB SCIEX, CA, USA).
The XIC manager tool in Master View ${ }^{\circledR}$ (AB Sciex, CA, USA) provided quasi-molecular weights, mass errors and isotope patterns. The possible compounds, their elemental compositions and chemical formulae could be calculated by screening the Chemspider database. ${ }^{35}$ The predicted formula with errors less than \pm 5 ppm was searched against the compounds reported for Usnea to obtain tentative identification.

\subsection{Analytical procedures}

The chemical compound identification strategy was based on a Triple TOF instrument with DBS-dependent on-line data acquisition and multiple post data-mining tools. The analytic strategy is presented in detail as follows: first, the mass spectrometry cracking behaviors of the reference substances were studied, and the fragmentation patterns were summarized. Second, a full mass scan was performed, and accurate MS/MS data sets were obtained using an effective MMDF and DBSdependent data acquisition method. The application of DBS could intelligently promote the ability of identification of drugrelated MS/MS ions from the background and matrix-related MS/MS ions. Therefore, the lower-level of target compounds could be clearly captured. Third, post-acquisition data mining was obtained by using various data mining tools including XIC, MDF, PIF, and NLF. Finally, the compounds were identified on the basis of accurate mass measurements and previously investigated fragmentation regulations of reference substances.

\subsection{Semi-quantitative data and chemometric analysis}

To evaluate the qualities of Usnea samples from different regions, a semi-quantitative analysis based on relative peak areas was introduced. PCA was applied to holistically observe the general clustering and trends among all samples using the SPSS 21.0 software (IBM SPSS, USA). The principal component (PC) score plots of the first 2 PCs were generated from the results of PCA.

\section{Results and discussion}

\subsection{Optimization of LC-MS/MS conditions}

With the purpose of achieving an efficient and rapid analysis, a high pressure chromatographic column packed with $2.6 \mu \mathrm{m}$ porous particles was applied in UPLC analysis. Different gradient elutions, flow rates $\left(0.3,0.4\right.$, and $\left.0.5 \mathrm{~mL} \mathrm{~min}^{-1}\right)$ and column temperatures $\left(20,25\right.$, and $\left.30{ }^{\circ} \mathrm{C}\right)$ were optimized to achieve a higher effect of chromatography and mass spectrometry. Meanwhile, to enhance the signal response, mobile phase modifiers such as formic acid and ammonium acetate were also evaluated. A mobile phase containing $0.1 \%$ formic acid and $4 \mathrm{mmoL} \mathrm{L}^{-1}$ ammonium acetate improved the chromatographic behavior, reduced the peak tailing and facilitated ionization. The mobile phase at $25{ }^{\circ} \mathrm{C}$ with a flow rate of 0.4 $\mathrm{mL} \min ^{-1}$ was finally selected for the shorter analysis. Thus, all the detected compounds could be well separated within 25 min. As shown in Fig. 1, the representative XIC spectra of standards and samples were obtained under the abovementioned optimized conditions. 
Furthermore, the mass spectrometric conditions were optimized in positive and negative ion modes. The negative ion mode was selected because the ionization of phenolic acids was more efficient when compared with the positive ion mode. The parameter $\mathrm{CE}$ was optimized to get the richest relative abundance by appropriate fragmentation and molecular intensity. Collision-induced dissociation (CID) combined with a CE of $-30 \mathrm{eV}$ and CES of $15 \mathrm{eV}$ was performed to obtain more fragmentation information for the elucidation of inferred compounds.
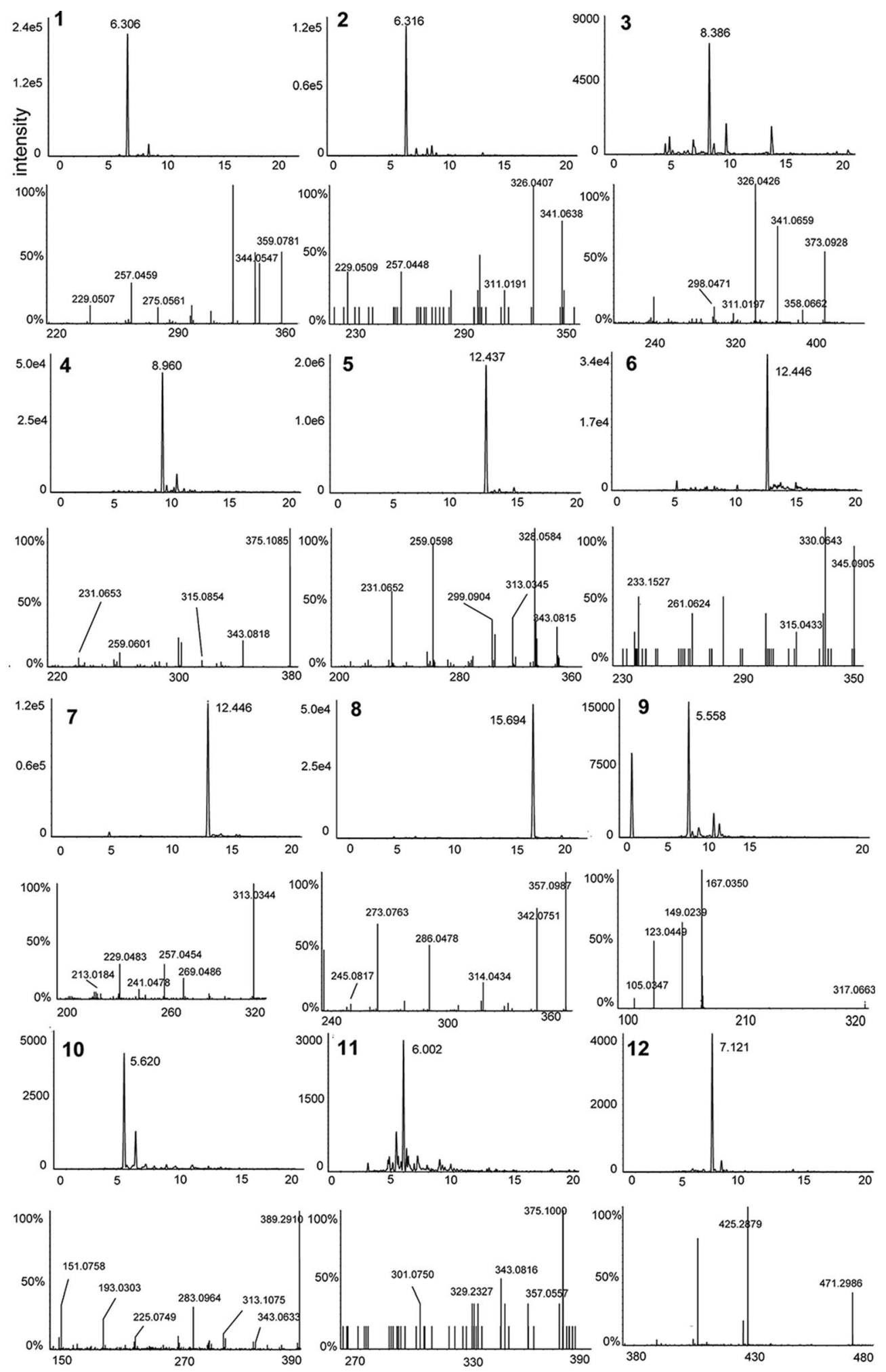

Fig. 1 The XIC and MS/MS spectra of samples. 

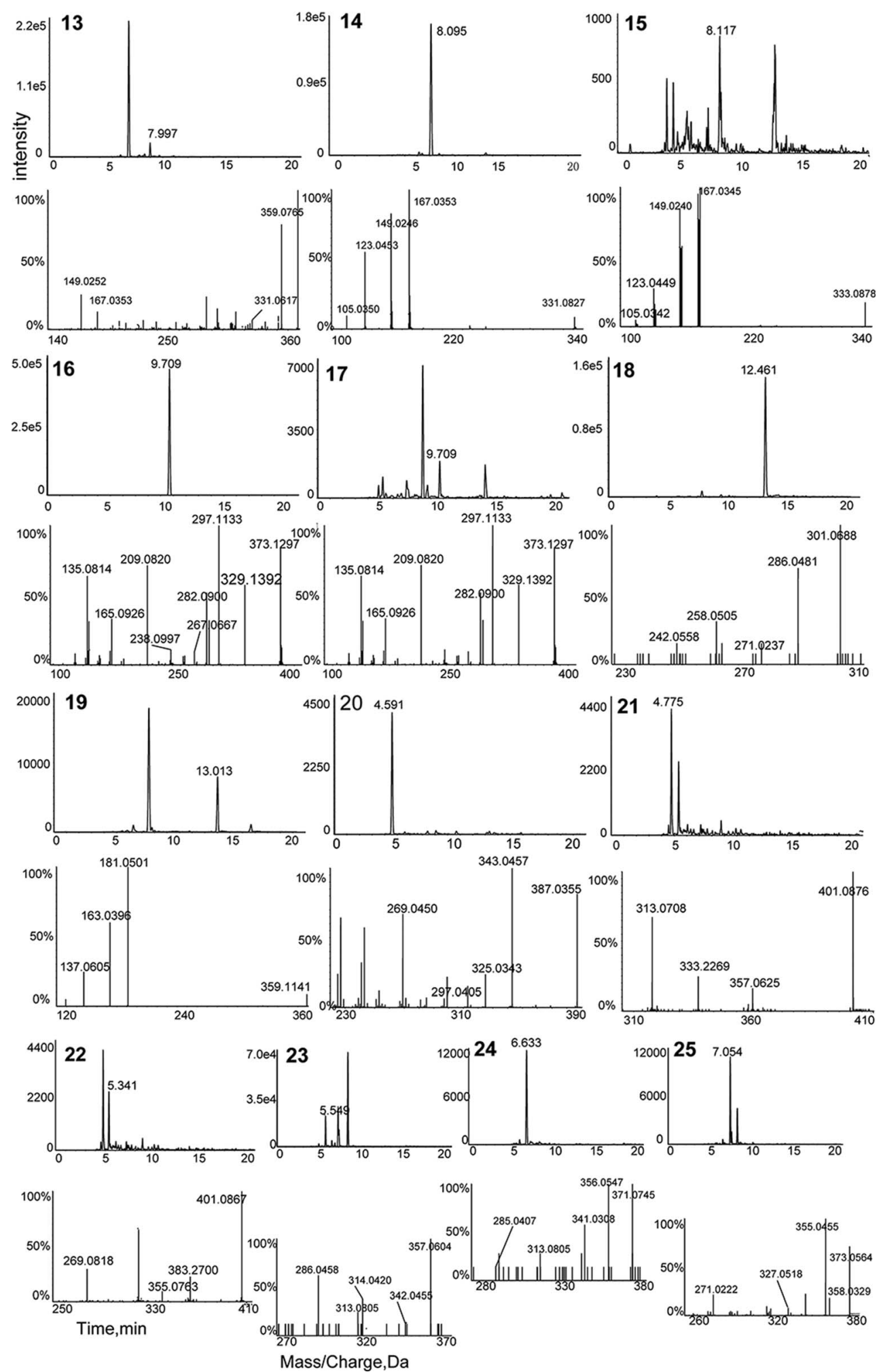

Fig. 1 (contd.)

\subsection{Establishment of qualitative analysis strategy}

All Usnea samples were detected using the optimized HRMS methods. To rapidly identify the target and non-target compounds in the Usnea extracts, a powerful integrated analytical strategy using on-line data acquisition combined with multiple data processing techniques including database searching, reference standard comparison, TOF-MS information, and MS/MS data analysis was first employed for the 

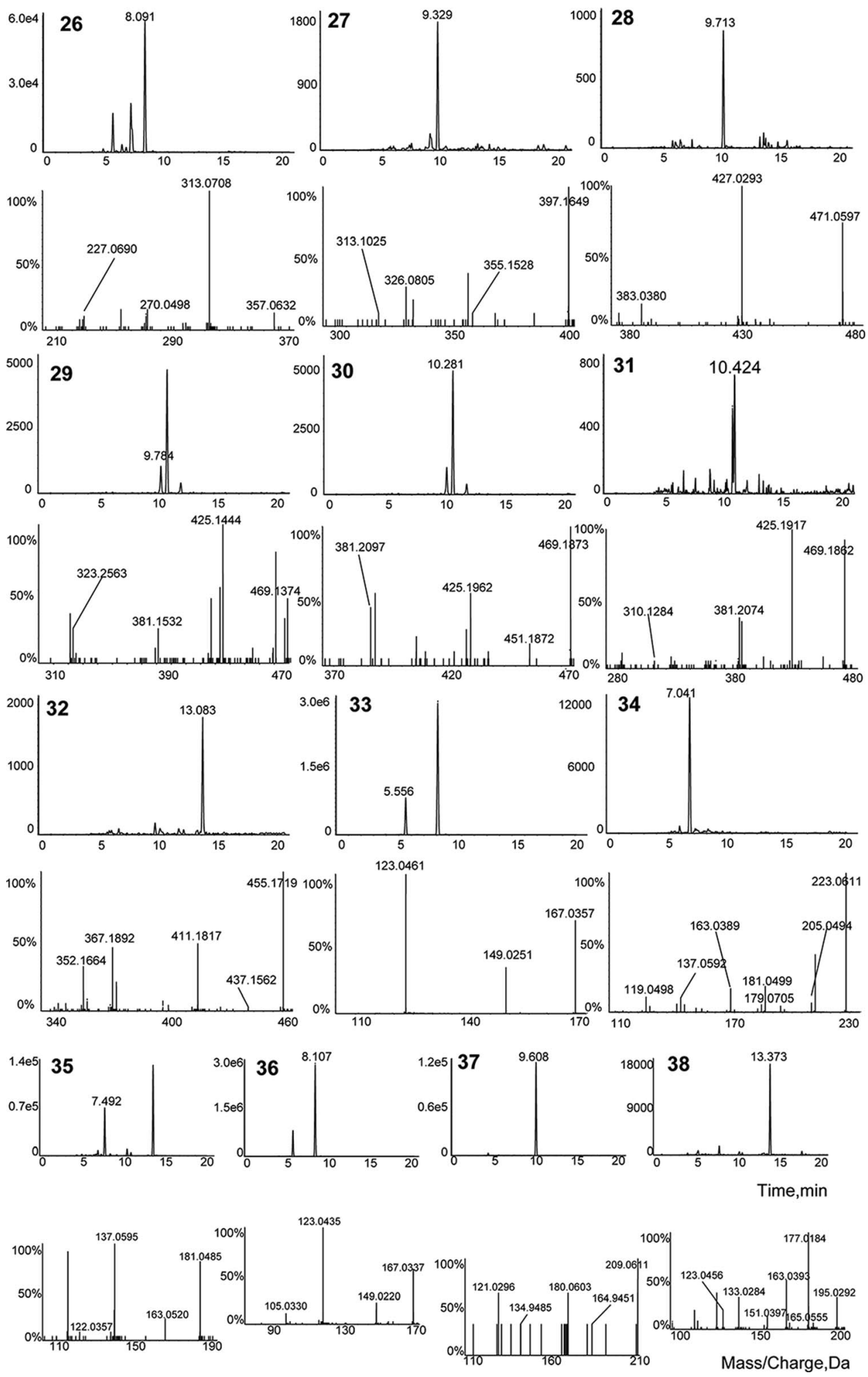

Fig. 1 (contd.)

unambiguous identification of constituents in the Usnea plant. The structures of the compounds having reference standards were deduced based on the retention times and HRMS data. At the same time, their cracking patterns were probed and summarized. On the contrary, the unknown constituents were deduced based on the high-accuracy $[\mathrm{M}-\mathrm{H}]^{-}$precursor ion in the negative ion mode using the XIC Manager software. The next step was to search for a possible compound in the 

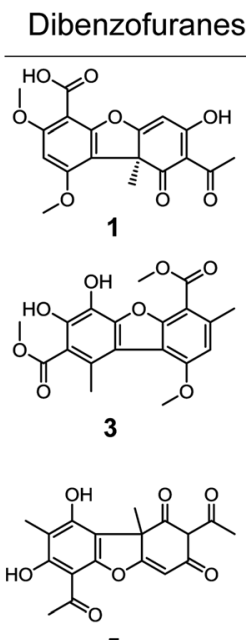

5

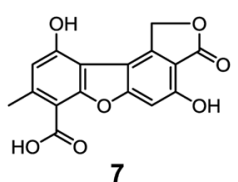

Didepsides
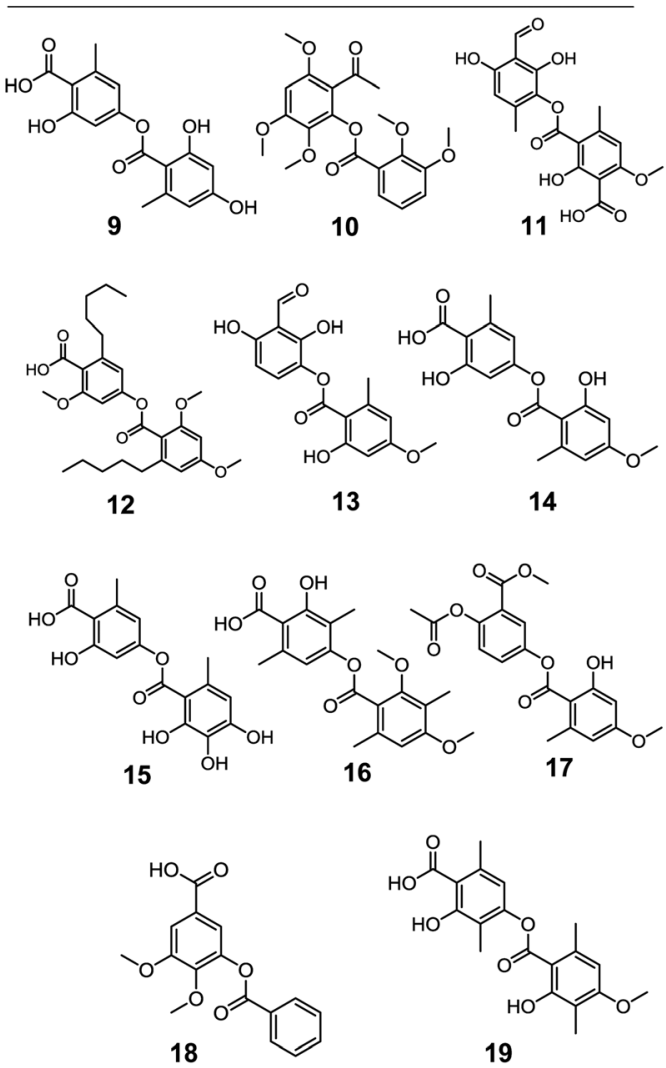

\section{Depsidones}
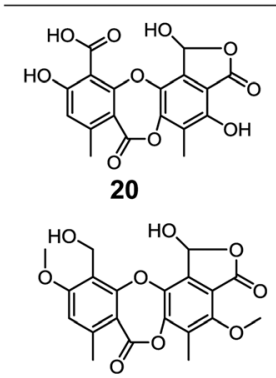

22

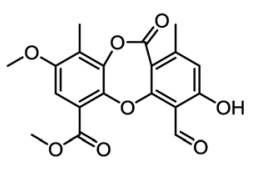

24<smiles>Cc1cc(O)c(C=O)c2c1OC(=O)c1c(C)c(O)c(C(=O)O)c(C)c1O2</smiles>

26

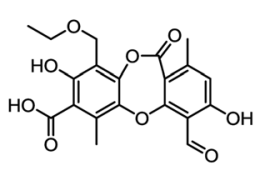

21<smiles>COc1cc(C(=O)O)c2c(C)c1OC(=O)c1c(C)cc(O)c(C=O)c1O2</smiles>

23<smiles>Cc1cc(O)c(CO)c2c1OC(=O)c1c(C)c(O)c3c(c1O2)C(O)OC3=O</smiles>

25

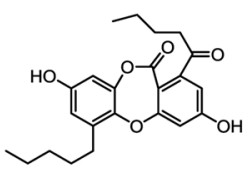

27<smiles>CCCCC(=O)Cc1c2c(cc(O)c1C(=O)O)C(=O)Oc1cc(OC)cc(c1CC(=O)CCC)C(=O)O2</smiles>

29

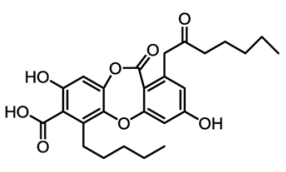

31

30

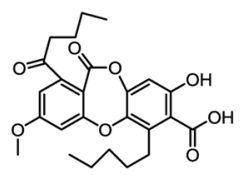

32

Mono-substituted phenyl rings

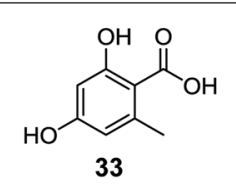<smiles>CCCC(=O)c1c(O)ccc(C(=O)O)c1O</smiles><smiles>COc1cc(C)c(C(=O)O)c(O)c1</smiles><smiles>COc1cc(C)c(C(=O)O)c(OC)c1</smiles>

38

Fig. 2 Chemical structures of 38 compounds identified in Usnea longissima Ach. 


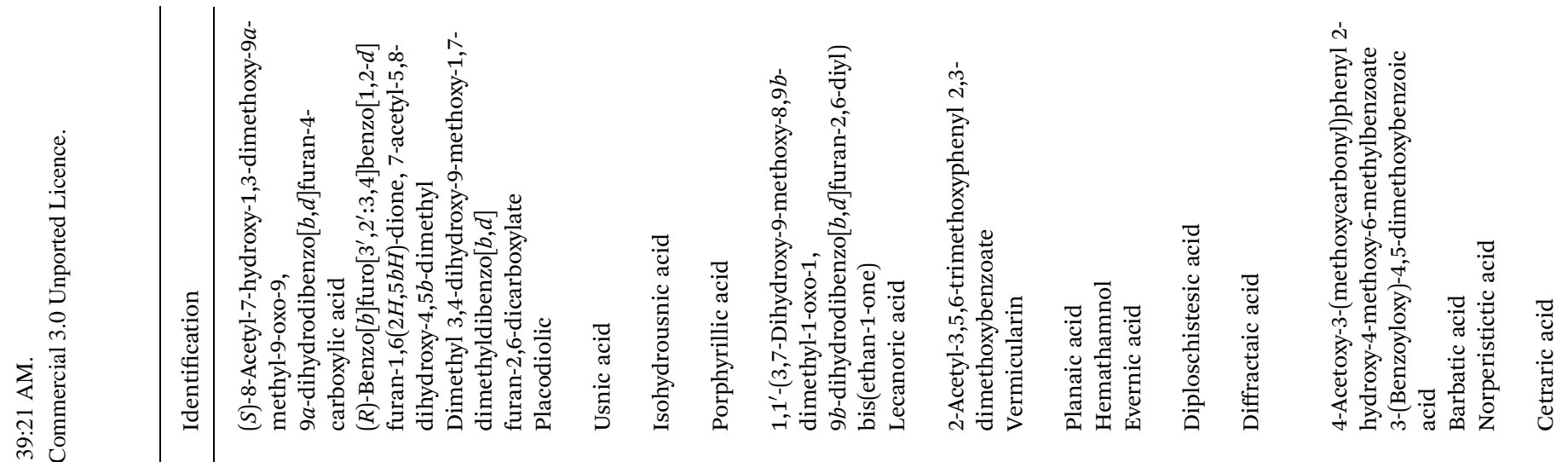

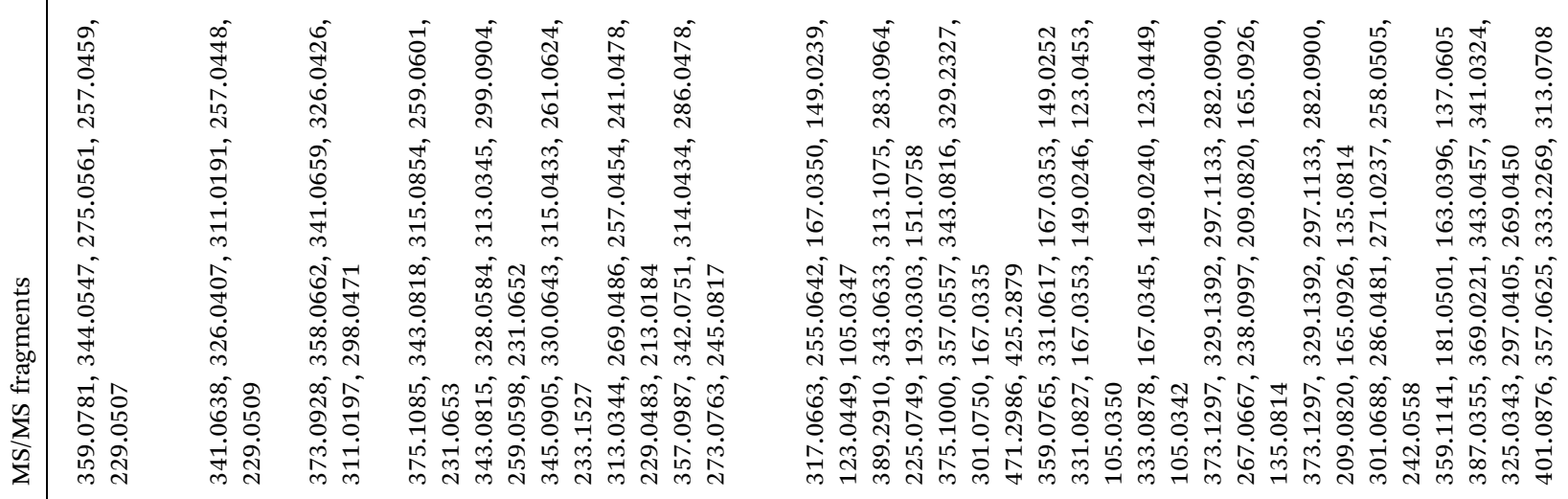

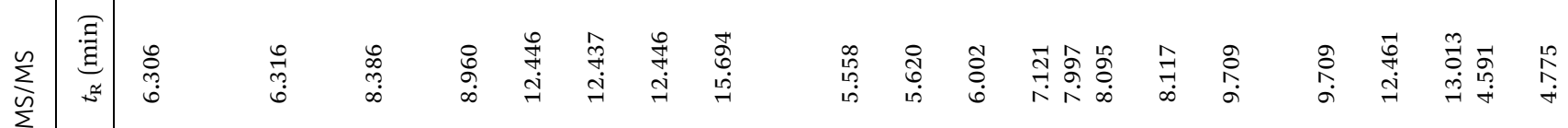

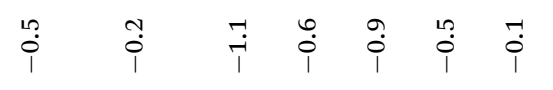

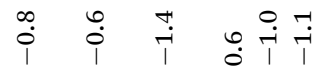

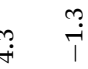

인

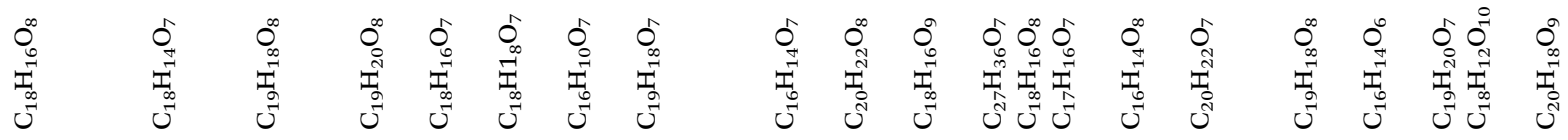

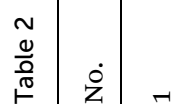




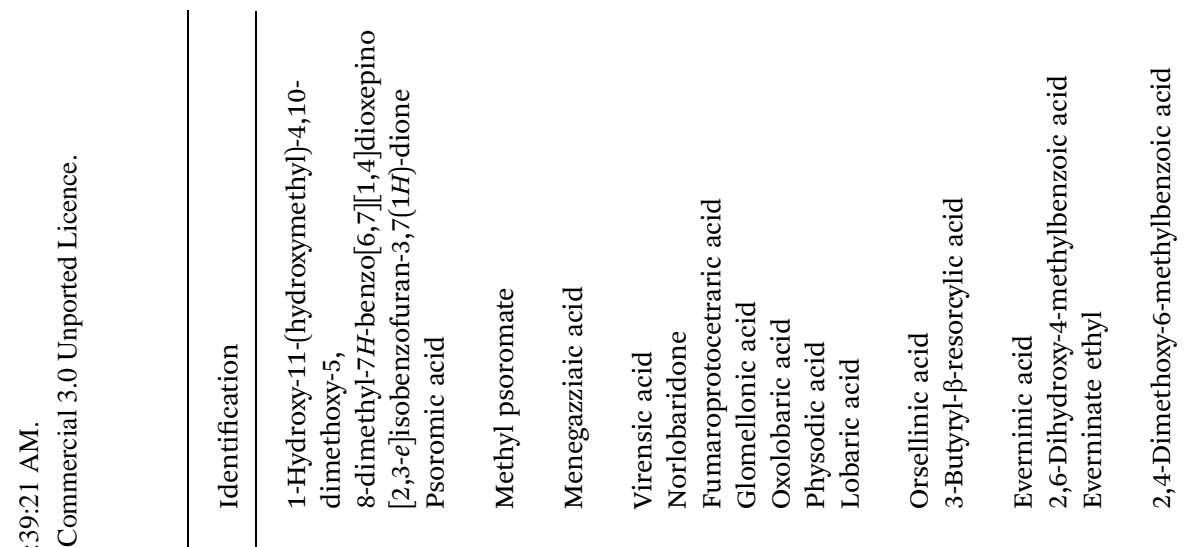

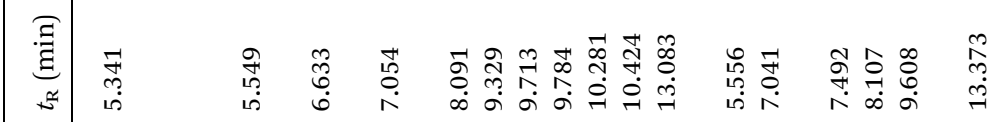

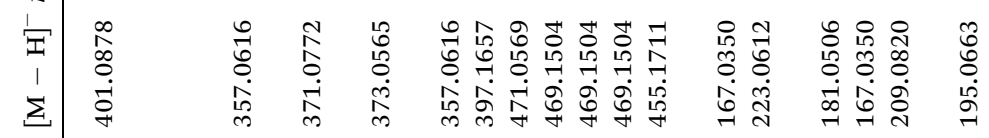

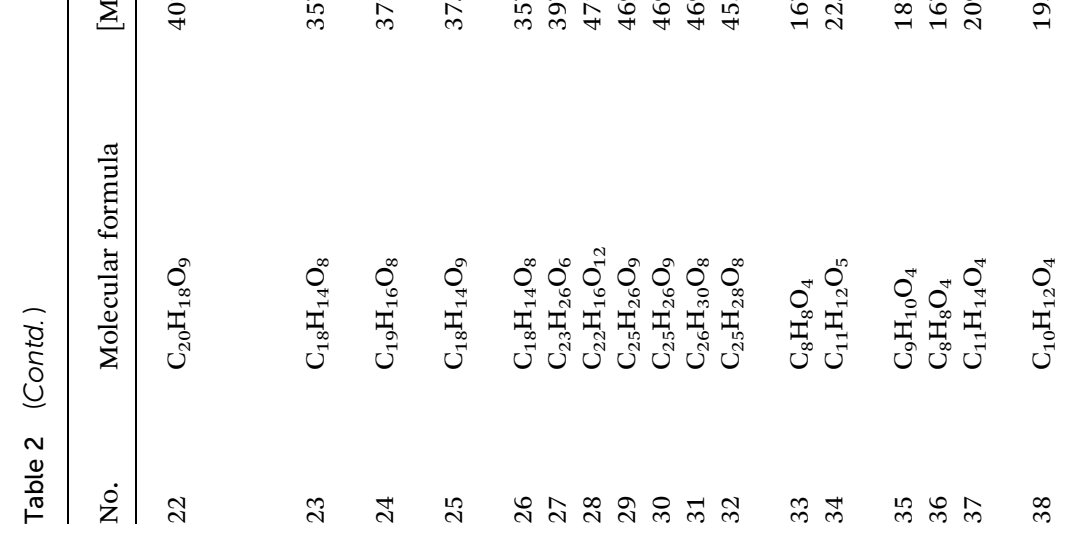


established Usnea characteristic components data set and then, the candidate structures were tentatively deduced from MS/MS spectrogram, the fragmentation patterns of reference standards, and the data of the reported literatures. As known, it is difficult to differentiate isomers because they have the same molecular formula. A certain degree of difference was presented in their retention times and chemical structures with lower energies. The minimized energy value and steric hindrance were used to account for the stability of the molecule. The minimized energy values were provided by the program ChemOffice 14.0 (CambridgeSoft, USA).

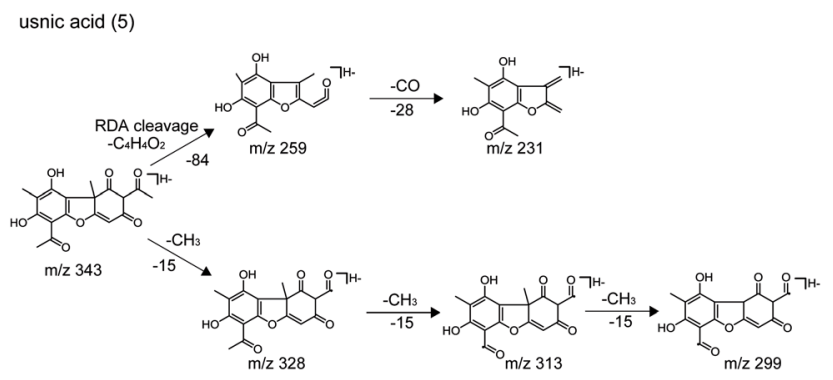

Fig. 3 The cleavage pathway of usnic acid.

\subsection{Compounds identified in Usnea}

Applying the abovementioned methods, a total of 38 components ( 8 dibenzofurans, 11 didepsides, 13 depsidones, and 6 mono-substituted phenyl rings) were identified in Usnea samples. Among them, three compounds (including usnic acid, diffractaic acid and evernic acid) were unambiguously characterized via comparison with chemical standards in terms of retention times and mass spectra. Their structures are shown in Fig. 2, and their detailed MS data are shown in Table 2.

3.3.1. Dibenzofurans. The dibenzofurans exhibited specific and abundant $[\mathrm{M}-\mathrm{H}]^{-}$precursor ions, and the negative ion MS/MS fragmentations of dibenzofurans were characterized by the Retro-Diels-Alder (RDA) cleavage of $\mathrm{C}_{1-12}$ and $\mathrm{C}_{2-3}$ bonds accompanied by the loss of characteristic fragments at $\mathrm{m} / \mathrm{z}$ $84 \mathrm{Da}\left(\mathrm{C}_{4} \mathrm{H}_{4} \mathrm{O}_{2}\right)$ and $m / z 112 \mathrm{Da}\left(\mathrm{C}_{5} \mathrm{H}_{4} \mathrm{O}_{3}\right) \cdot{ }^{36}$ Multiple neutral loss pathways always occur in dibenzofurans. Taking usnic acid (5) as an example, the predominant quasi-molecular ion $[\mathrm{M}-\mathrm{H}]^{-}$ at $m / z 343.0823$ gave the formula $\mathrm{C}_{18} \mathrm{H}_{16} \mathrm{O}_{7}$, and the product fragments observed at $m / z 259\left(\left[\mathrm{M}-\mathrm{H}-\mathrm{C}_{4} \mathrm{H}_{4} \mathrm{O}_{2}\right]^{-}\right)$and $231([\mathrm{M}-\mathrm{H}-$ $\left.\mathrm{C}_{5} \mathrm{H}_{4} \mathrm{O}_{3}\right]^{-}$) corresponded to their RDA cleavage. Furthermore, distinctive product ions at $\mathrm{m} / \mathrm{z} 328,313$, and 299 were detected in the spectrum of usnic acid due to the continuous loss of $\mathrm{CH}_{3}$ (15 Da) and $\mathrm{CH}_{2}(14 \mathrm{Da})$ units from the deprotonated molecule at $m / z$ 343. Based on the above reference, 7 compounds were

A: evernic acid (14)

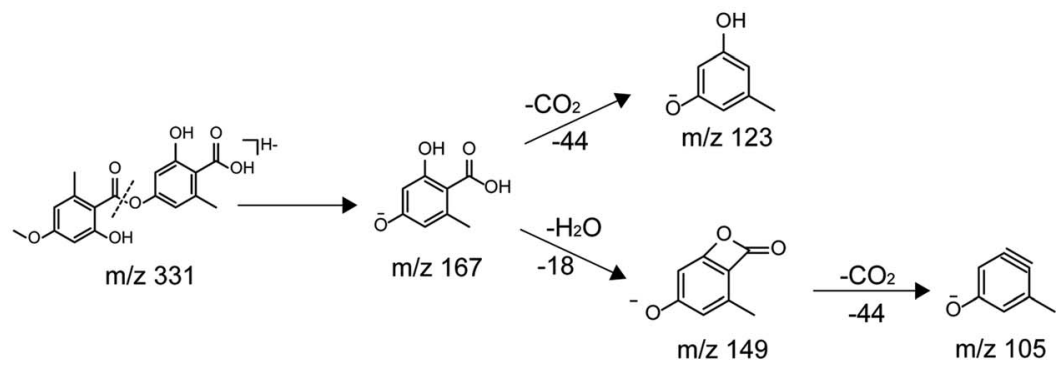

B: diffractaic acid (16)

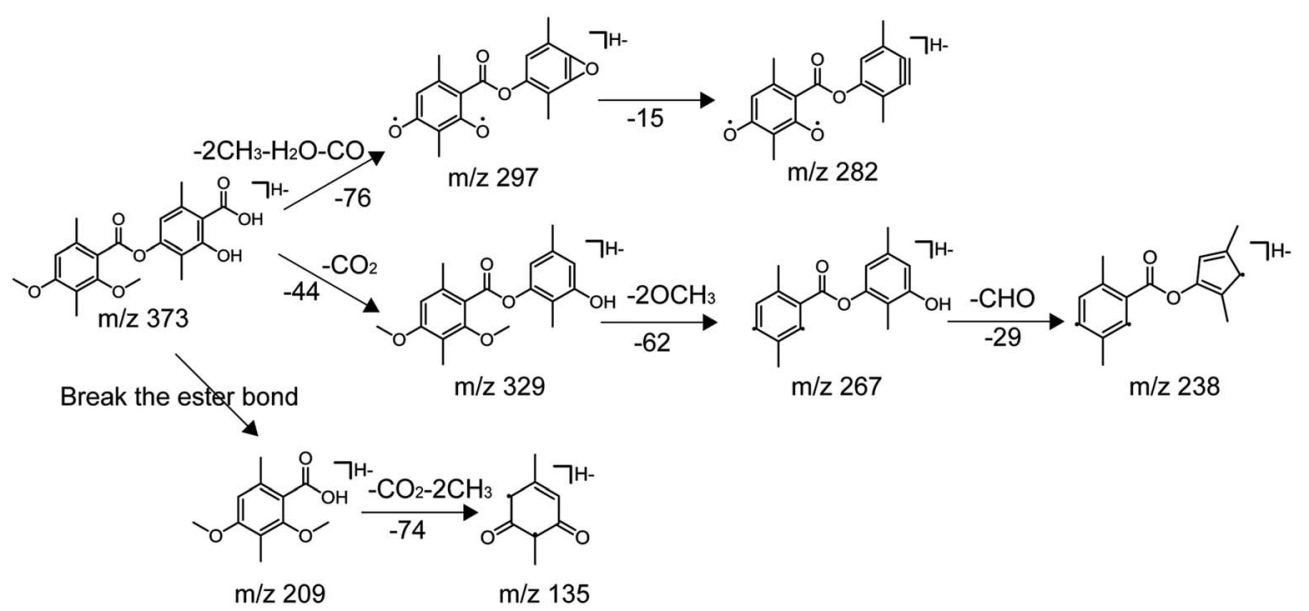

Fig. 4 The cleavage pathways of phenyl salicylate, evernic acid and diffractaic acid 
briefly identified by comparison with usnic acid in terms of the fragmentation patterns. Compounds 1, 2, 6, and 8 demonstrated a distinctive $\mathrm{C}_{4} \mathrm{H}_{4} \mathrm{O}_{2}$ loss and $\mathrm{C}_{5} \mathrm{H}_{4} \mathrm{O}_{3}$ loss from the parent ion. Compound $\mathbf{4}$ readily produced a strong fragment ion $\left[\mathrm{M}-\mathrm{H}-\mathrm{CH}_{4} \mathrm{O}\right]^{-}(\mathrm{m} / \mathrm{z} 343)$, which yielded the structure of incidental RDA cleavage and then generated the fragment ion at $\mathrm{m} / \mathrm{z} 259$ and 231. Thus, compound 4 was confirmed to be placodiolic acid (Fig. 3). Moreover, compounds 3 and 7 presented neutral losses of $\mathrm{CH}_{3}$, $\mathrm{CO}$, and $\mathrm{CO}_{2}$ molecules.

3.3.2. Didepsides. A large number of didepsides were identified in the Usnea samples. Most of these compounds were substituted with phenyl salicylate, and they yielded salicylic acid ion A and phenol moiety ion B by breaking the ester bonds of the eight-membered ring transition state rearrangements. Evernic acid and diffractaic acid were used as examples to explore and verify the fragmentation patterns of these didepsides in detail. In the MS/MS spectra of the reference standard of evernic acid (14), minor product ion was detected at $m / z 164$, and the ion B at $\mathrm{m} / \mathrm{z} 167$ corresponded to the cleavage of the ester bond. Then, the distinctive fragment ions at $\mathrm{m} / \mathrm{z} 149$ and 123 were formed by the losses of $\mathrm{H}_{2} \mathrm{O}$ and $\mathrm{CO}_{2}$, respectively, from ion B (Fig. 4A). Another typical instance was the reference standard of diffractaic acid (16), which yielded identical product ions at $m / z 329,297,282,267$, and 238 through consecutive losses of neutral molecules such as $\mathrm{CO}_{2}, \mathrm{CH}_{4} \mathrm{O}, \mathrm{CH}_{2} \mathrm{O}, \mathrm{CH}_{3}$, and $\mathrm{CHO}$, respectively. At the same time, the fragment ions at $\mathrm{m} / \mathrm{z}$ 209 and 165 were observed by breaking the ester bond (Fig. 4B). Accordingly, the results validated the abovementioned summarized fragmentation regularities. A comparison with the cracking rules of reference standards and literature data ${ }^{37}$ resulted in the compounds $9,10,11,12,13,15,17,18$, and 19 being unequivocally identified.

3.3.3. Depsidones. The depsidones from the Usnea samples were characterized based on the literature data. ${ }^{37}$ Similar to the structure of didepsides, the molecular structure of these compounds possessed a diphenyl ether bond between the A ring and B ring, which hindered the simple cracking of the ester bond. The decarboxylation reaction and dehydration reaction, especially the decarboxylation reaction, could occur when the $\mathrm{B}$ ring had the structure of salicylic acid. The continuous pyrolysis loss of $\mathrm{H}_{2} \mathrm{O}$ and $\mathrm{CO}$ mainly occurred when the carboxyl group of phenolic moieties entered the state of lactones. According to the abovementioned evidence, 13 depsidones were identified by the summarized fragmentation patterns combined with product ions observed in the MS/MS spectra. These summarized cleavage features assisted in the identification of the unknown compounds 20-32. Taking lobaric acid (32) as an example, the predominant quasi-molecular ion $[\mathrm{M}-\mathrm{H}]^{-}$at $\mathrm{m} / \mathrm{z} 455.1711$ could be detected in the TOF-MS spectrum, giving the formula of $\mathrm{C}_{25} \mathrm{H}_{28} \mathrm{O}_{8}$. Further evidence was obtained from the negative MS/MS fragmentation of the characteristic ion at $m / z 411$ ([M$\left.\mathrm{H}-\mathrm{CO}_{2}\right]^{-}$) (Fig. 5A). The unknown compound physodic acid (31) underwent similar cleavage pathways as those of 32, corresponding to the quasi-molecular ion $[\mathrm{M}-\mathrm{H}]^{-}$at $\mathrm{m} / \mathrm{z} 469.1868$ and the $\mathrm{M}-44$ peak at $m / z 425\left(\left[\mathrm{M}-\mathrm{H}-\mathrm{CO}_{2}\right]^{-}\right)$. In addition, compounds 21, 23, 24, 26, 27, 28, 29, and 30 showed similar MS data, thereby suggesting that these analytes were also depsidones. Another classic example was the unknown compound

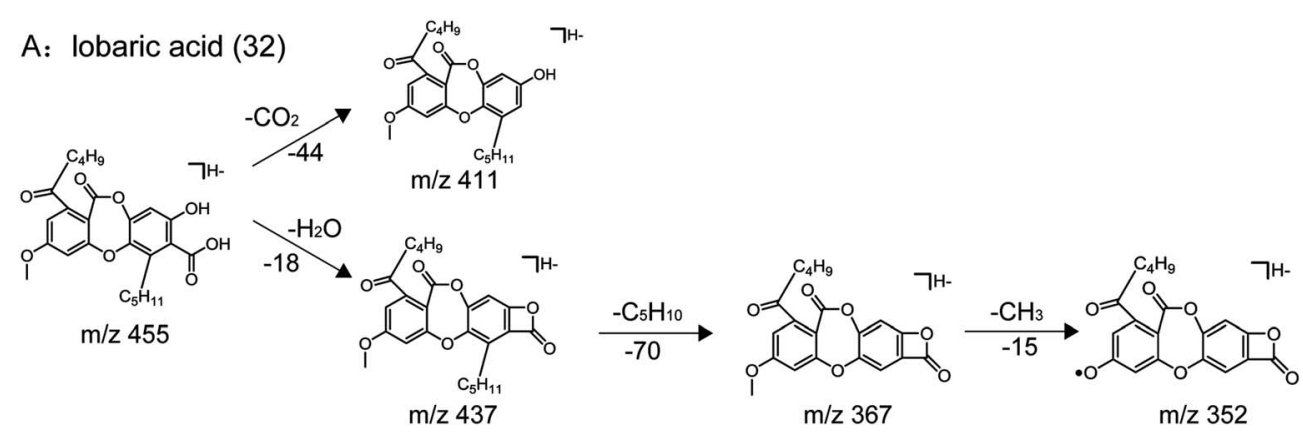

B: menegazziaic acid (25)

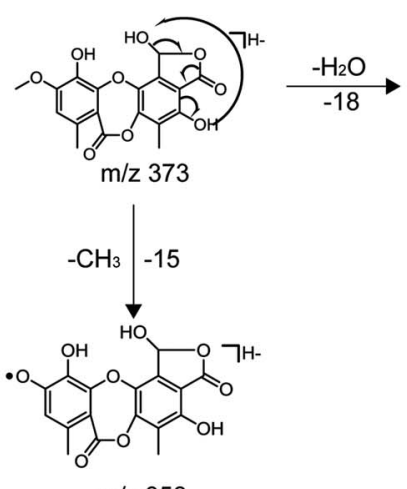

$\mathrm{m} / \mathrm{z} 358$
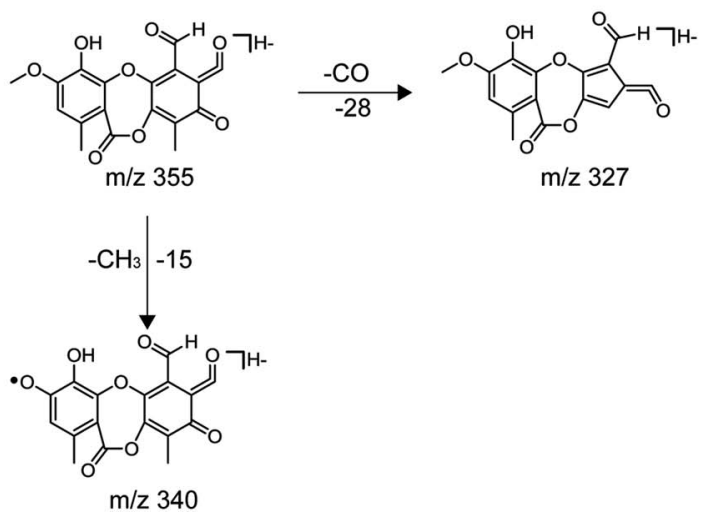

Fig. 5 The cleavage pathways of lobaric acid and menegazziaic acid. 
(25), which displayed the $[\mathrm{M}-\mathrm{H}]^{-}$precursor ion at $\mathrm{m} / \mathrm{z}$ $373.0565\left(\mathrm{C}_{18} \mathrm{H}_{14} \mathrm{O}_{9}\right)$. It yielded abundant product ions at $\mathrm{m} / \mathrm{z}$ 355 and $\mathrm{m} / \mathrm{z} 327$ corresponding to the continuous loss of $\mathrm{H}_{2} \mathrm{O}$ and CO molecules, and this was in close agreement with the fragment pathway of depsidones (Fig. 5B). Consequently, compound 25 was identified as menegazziaic acid based on the abovementioned evidence. In a similar manner, compounds $\mathbf{2 0}$ and 22 exhibited similar fragmentation pathways to produce $\left[\mathrm{M}-\mathrm{H}-\mathrm{H}_{2} \mathrm{O}\right]^{-}$and $\left[\mathrm{M}-\mathrm{H}-\mathrm{H}_{2} \mathrm{O}-\mathrm{CO}\right]^{-}$fragments, respectively, in the negative mode.

3.3.4. Mono-substituted phenyl rings. The monosubstituted phenyl rings displayed specific and abundant [M $-\mathrm{H}]^{-}$quasi-molecular ions, of which the MS/MS fragmentation featured successive losses of $\mathrm{CO}_{2}$ and $\mathrm{H}_{2} \mathrm{O}$ as illustrated by the representative compound 33 shown in Fig. 6. The compound 33 $\left(t_{\mathrm{R}}=5.56 \mathrm{~min}\right)$ exhibited the $[\mathrm{M}-\mathrm{H}]^{-}$precursor ion at $\mathrm{m} / \mathrm{z}$ 167.0357. The typical product ions at $m / z 149\left(\left[\mathrm{M}-\mathrm{H}-\mathrm{H}_{2} \mathrm{O}\right]^{-}\right), 123$ $\left(\left[\mathrm{M}-\mathrm{H}-\mathrm{CO}_{2}\right]^{-}\right)$, and $105\left(\left[\mathrm{M}-\mathrm{H}-\mathrm{CO}_{2}-\mathrm{H}_{2} \mathrm{O}\right]^{-}\right)$were observed in the HRMS data. Thus, the compound $\mathbf{3 3}$ was tentatively assigned as orsellinic acid after comparison with the data in the literature. Likewise, the compounds $34,35,36,37$, and 38 were tentatively characterized based on the HRMS information, database searching sets, differentiated retention behavior, and previous literatures. ${ }^{36}$ By comparing with the MS data and the results of previous studies, compounds 34, 35, 36, 37, and 38 were tentatively assigned as 3-butyryl- $\beta$-resorcylic acid, everninic acid, 2,6-dihydroxy-4-methylbenzoic acid, everninate ethyl and 2,4-dimethoxy-6-methylbenzoic acid, respectively.

\subsection{Semi-quantitative analysis of Usnea samples}

To overcome the serious restriction due to lack of reference standards, a feasible semi-quantitative approach on the single herb was developed to evaluate the differences in the qualities of Usnea samples. It was reported that semi-quantitative analysis was successfully used to assess the quality of different batches of the Niuhuang Shangqing pill; ${ }^{38}$ this analysis could compare the differences between the qualities of various batches. Thus, a semi-quantitative assay was introduced to appraise the similarities and differences in the qualities of the 25 batches of Usnea samples obtained from different sources. At the same time, the main chemical markers affecting the quality of this herb were checked out. In regard to semi-quantitation of Usnea samples, peaks of 38 compositions in the 25 batches were identified and then, their absolute peak areas were recorded in succession. Meanwhile, sample no. 1 was selected as the

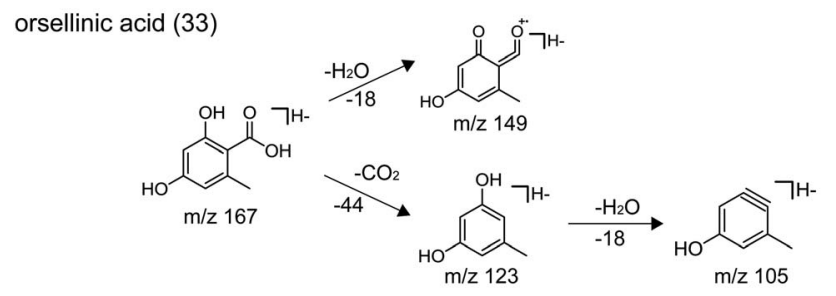

Fig. 6 The cleavage pathway of orsellinic acid. reference sample based on the previous quantitative study by HPLC-ESI-MS/MS. ${ }^{22}$ After the absolute peak areas of 38 compounds in the other 24 samples were respectively divided by those in sample no. 1 , the relative peak areas (RPAs) were obtained. The absolute peak areas and the relative peak areas of 38 compounds are presented in Tables S1 and S2, $\dagger$ respectively.

To further evaluate the quality differences and find the possible characteristic components in Usnea samples, PCA was performed on the basis of the calculated RPAs, and the results exhibited remarkable group segregations and potentially significant components. The first two principle components (PC1 and PC2) with more than $75.2 \%$ of the total variance were extracted for analysis; among them, PC1 accounted for $56.9 \%$ of the variance and $\mathrm{PC} 2$ accounted for $18.3 \%$ of the variance. As seen in Table S3, $\uparrow$ PC1 included strong contributions from most components except the compounds 3, 8, 13, 21, 22, and 29; PC2 was directly correlated with the compounds $\mathbf{3}$ and $\mathbf{8}$. Consistent with the above-mentioned direct data, a graphical illustration is also presented in Fig. 7A. Compound $\mathbf{5}$ and other compounds such as 1, 2, 6, 7, 9, 11, 12, 18, 20, 24, 25, 27, 32, and 34 were located apart from the above-mentioned components. The
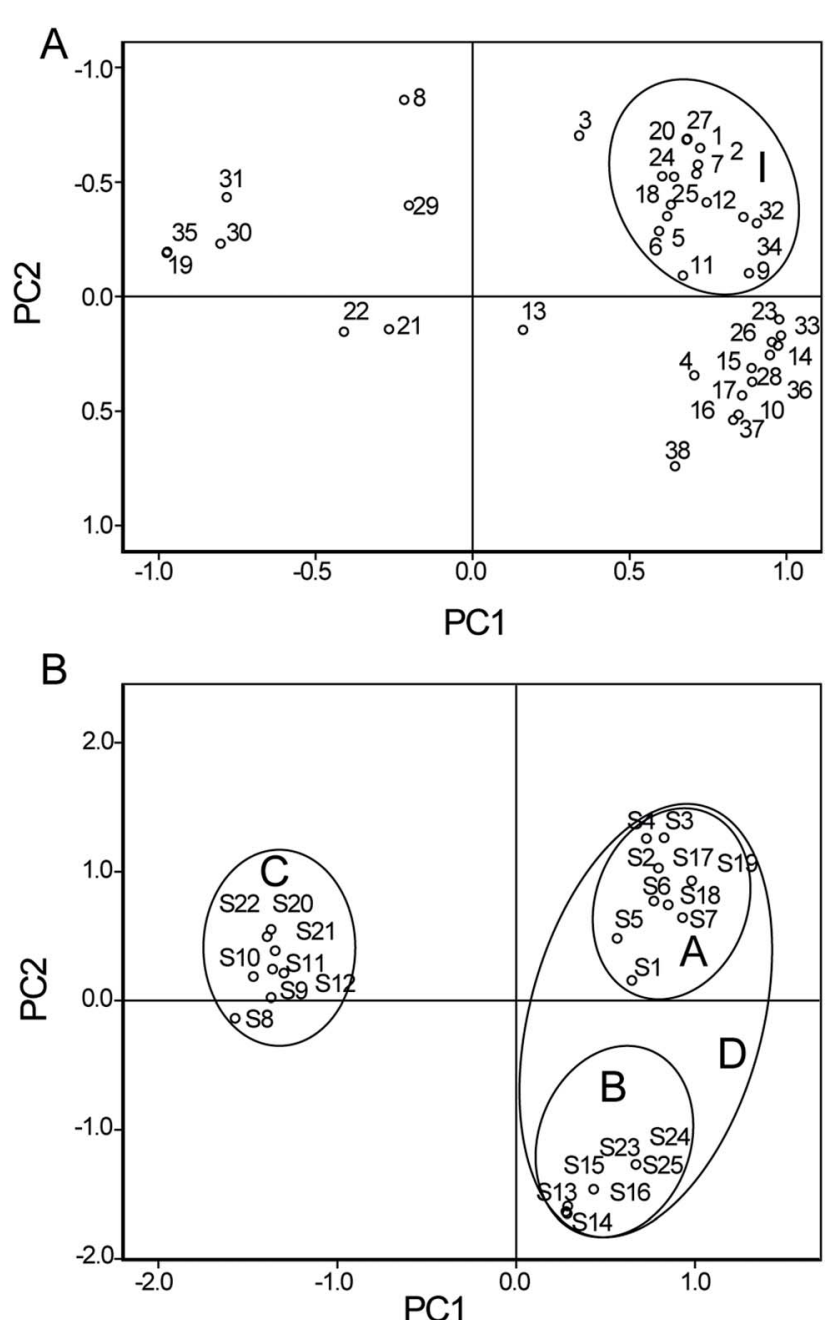

Fig. 7 Loading plots (A) and score plots (B) for the compounds of Usnea longissima Ach. obtained from different origins. 
results suggested that the compounds $1,2,6,7,9,11,12,18,20$, $24,25,27,32$, and 34 might be the possible diagnostic chemical markers in Usnea samples like usnic acid (5). Pharmacological experiments have proved that usnic acid is a natural active ingredient in Usnea and a broad-spectrum anti-bacterial component. Thus, the consideration of the compounds together with usnic acid as quantitative indicators for further quality control of Usnea herbs is very meaningful. ${ }^{39,40}$

As can be seen clearly in Fig. 7B, all the samples were clearly clustered in three domains. Samples S1-S7 and S17-S19 were in circle A (from Sichuan province in China), samples S8-S12 and S20-S22 were in circle B (from Yunnan province in China), and samples S13-S16 and S23-S25 were in circle C (from Zhejiang province in China). The results showed that there was a quality difference in Usnea herbs obtained from different origins. Moreover, the circle D characterized by positive scores on PC1 was located apart from circle $\mathrm{B}$, which suggested potential similarities between the qualities of Usnea samples obtained from the Yunnan province and Sichuan province. It was also plausible that the place of origin could have an impact on the quality of Usnea.

\section{Conclusions}

A novel analysis strategy based on UHPLC-Q-TOF-MS/MS integrated with multivariate statistical analysis methods was developed and used for the holistic quality control of Usnea herbs. The fragmentation patterns of phenolic acids in Usnea were summarized for the first time. A total of 38 phenolic compounds (8 dibenzofurans, 11 didepsides, 13 depsidones, and 6 mono-substituted phenyl rings) were identified. Then, a semi-quantitative analysis was performed in Usnea samples, and PCA was conducted to evaluate the quality of the Usnea samples. The results showed that there were obvious differences in the qualities of the Usnea samples obtained from different regions, and the main factors influencing these qualities were picked out. The proposed method provided a solution for the comprehensive quality assessment of not only Usnea herbs but also other TCMs.

\section{Funding sources}

This study received financial support from the National Natural Science Foundation of China (No. 81402894), the Key Projects of Hebei Education Department (No. ZD2017244), the Project of Hebei Province Food and Drug Administration (No. ZD2015021, No. ZD2015029) and the Project of Hebei Province Traditional Chinese Medicine Administration (No. 2014139).

\section{Conflicts of interest}

The authors declare no competing financial interest.

\section{Acknowledgements}

Thanks for instrument support from the Department of Pharmaceutical Analysis, School of Pharmacy, Hebei Medical University.

\section{References}

1 C. Bezivin, S. Tomasi, F. L. Devehat and J. Boustie, Phytomedicine, 2003, 10, 499-503.

2 B. Simon-Haarhaus and C. M. Schempp, J. Photochem. Photobiol., B, 2007, 89, 9-14.

3 I. Zizovic, J. Ivanovic, D. Misic, M. Stamenic, S. Djordjevic and J. Kukic-Markovic, J. Supercrit. Fluids, 2012, 72, 7-14.

4 F. Rancan, S. Rosan, K. Boehm, E. Fernandez and M. E. Hidalgo, J. Photochem. Photobiol., B, 2002, 68, 133-139.

5 Y. Yamamot, Y. Miura, Y. Kinoshita, M. Higuchi, Y. Yamada, A. Murakami, H. Ohigashi and K. Koshimizu, Chem. Pharm. Bull., 1995, 43, 1388-1390.

6 M. Halici, F. Odabasoglu, H. Suleyman, A. Cakir, A. Aslan and Y. Bsyir, Phytomedicine, 2005, 12, 656-662.

7 I. C. Muhammad, J. S. Azizuddin and U. R. Atta, Phytochemistry, 2005, 66, 2346-2350.

8 Y. Q. Su, H. H. Wang, Y. M. Ma, R. Q. Li, G. Koichiro and M. Shinji, J. Northwest Univ., 2006, 21, 154-155.

$9 \mathrm{~J}$. Li, Preparation of Chinese medicinal oral liquid containing green tea for preventing and treating oral ulcer, Faming Zhuanli Shenqing, 2014, CN 104173885 A 20141203.

10 G. Wang, Method for preparing spiral black tea (usnea), Faming Zhuanli Shenqing, 2010, CN 101715857 A 20100602.

11 S. Cheng, A health tea with effects of clearing away liver heat and purging pathogenic fire and its preparation method, Faming Zhuanli Shenqing, 2010, CN 101715857 A 20100602.

12 Y. Nishitoba, I. Nishimura, T. Nishiyama and J. Mizutani, Phytochemistry, 1987, 26, 3181-3185.

13 Laxinamujila, H. J. Bao and T. Bau, Zhongguo Zhongyao Zazhi, 2013, 38, 539-545.

14 Y. Bayir, F. Odabasoglu, A. Cakir, A. Aslan, H. Suleyman, M. Halici and C. Kazaz, Phytomedicine, 2006, 13, 584-590.

15 K. R. Thallita, E. C. Fares, M. V. Laura, P. A. D. S. Joao, F. D. R. Ricardo, A. D. B. H. P. Matheus, L. R. F. Jose, A. S. A. Adriano, C. F. M. Jose and P. G. Daniel, Toxicol. in Vitro, 2012, 26, 304-314.

16 A. A. Shtro, V. V. Zarubaev, O. A. Luzina, D. N. Sokolov, O. I. Kiselev and N. F. Salakhutdinov, Bioorg. Med. Chem., 2014, 22, 6826-6836.

17 M. P. Polovinka, M. T. Egorycheva, N. G. Vlasenko and N. F. Salakhutdinov, Khim. Interesakh Ustoich. Razvit., 2012, 20, 713-720.

18 M. A. Fanovich, J. Ivanovic, I. Zizovic, D. Misic and D. Jaeger, Mater. Sci. Eng., C, 2016, 58, 204-212.

19 Y. H. Ma, T. T. Tian, W. W. Xie, Y. R. Jin, H. J. Xu, L. T. Zhang and Y. s F. Du, Chin. Tradit. Herb. Drugs, 2016, 47, 392-400.

20 H. M. Zhang, S. L. Li, H. Zhang, Y. Wang, Z. L. Zhao, S. L. Chen and H. X. Xu, J. Pharm. Biomed. Anal., 2012, 62, 258-273. 
21 J. Jin, Y. B. Li, E. K. Tanui, L. W. Han, Y. Jia, L. Zhang, Y. M. Wang, X. X. Zhang and Y. J. Zhang, J. Ethnopharmacol., 2013, 147, 357-365.

22 Y. H. Ma, T. T. Tian, W. W. Xie, Y. R. Jin, H. J. Xu, L. T. Zhang and Y. F. Du, Zhongguo Zhongyao Zazhi, 2015, 40, 4884-4889.

23 M. F. Fang, H. Wang, Y. Wu, Q. L. Wang, X. F. Zhao, X. H. Zheng, S. X. Wang and G. F. Zhao, Bull. Korean Chem. Soc., 2013, 34, 1684-1688.

24 C. V. N. S. Silva, M. S. Ferraz, N. K. Honda, M. C. B. Lira and N. S. Santos-Magalhaes, Lat. Am. J. Pharm., 2012, 31, 120124.

25 L. Yi, Y. L. Ouyang, X. Sun, N. Y. Xu, R. J. Linhavalt and Z. Q. Zheng, J. Chromatogr. A, 2015, 1423, 79-85.

26 J. A. Padilla-Sanchez and L. S. Haug, J. Chromatogr. A, 2016, 1445, 36-45.

27 L. L. He, Z. F. Zhang, L. Y. Lu, Y. Liu, S. Li, J. G. Wang, Z. J. Song, Z. G. Yan and J. H. Miao, J. Pharm. Biomed. Anal., 2016, 117, 125-139.

28 Y. X. Wang, H. P. Hao, G. J. Wang, P. F. Tu, Y. Jiang, Y. Liang, L. Pai, H. Yang, L. Lai, C. N. Zheng, Q. Wang, N. Cui and Y. T. Liu, Talanta, 2009, 80, 572-580.

29 W. Si, W. Z. Yang, D. Guo, J. Wu, J. X. Zhang, S. Qiu, C. H. Yao, Y. J. Cui and W. J. Wu, J. Pharm. Biomed. Anal., 2016, 117, 510-521.

30 M. A. Farag, S. T. Sakna, N. M. El-fiky, M. M. Shabana and L. A. Wessjohann, Phytochemistry, 2015, 119, 41-50.
31 Z. F. Zhang, L. L. He, L. Y. Lu, Y. Liu, G. T. Dong, J. H. Miao and P. Luo, J. Pharm. Biomed. Anal., 2015, 109, 62-66.

32 T. Xie, Y. Liang, H. P. Hao, A. Jiye, L. Xie, P. Gong, C. Dai, L. S. Liu, A. Kang, X. Zheng and G. J. Wang, J. Chromatogr. A, 2012, 1227, 234-244.

33 S. J. Li, H. Lin, C. Qu, Y. P. Tang, J. Shen, W. X. Li, S. J. Yue, J. Kai, G. X. Shang, Z. H. Zhu, C. B. Zhang, P. Liu, H. Yan, L. Zhang, L. Qian, D. W. Qian and J. A. Duan, J. Ethnopharmacol., 2015, 170, 175-183.

34 W. J. Zhou, J. Z. Song, W. W. Fu, H. S. Tan, Z. X. Bian and H. X. Xu, J. Pharm. Biomed. Anal., 2013, 84, 59-68.

35 A. Masia, M. Ibanez, C. Blasco, J. V. Sancho, Y. Pico and F. Hernandez, Anal. Chim. Acta, 2013, 761, 117-127.

36 C. X. Yin, C. Li, L. Peng, L. L. Tang, M. Z. Yang, H. Zhang and Y. L. Xiao, J. Yunnan Nor. Univ., 1996, 16, 56-61.

37 P. Z. Cong and S. Y. Li, Natural Organic Spectroscopy, 2002, pp. 1284-1296.

38 D. D. Wang, J. Liang and W. Z. Yang, J. Pharm. Biomed. Anal., 2014, 89, 130-141.

39 V. Taresco, I. Francolini, F. Padella, M. Bellusci, A. Boni, C. Innocenti, A. Martinelli, L. Pllario and A. Piozzi, Mater. Sci. Eng. C, 2015, 52, 72-81.

40 Z. Q. Su, Z. Z. Mo, J. B. Liao, X. X. Feng, Y. Z. Liang, X. Zhang, Y. H. Liu, X. Y. Chen, Z. W. Chen, Z. R. Su and X. P. Lai, Int. Immunopharmacol., 2014, 22, 371-378. 